\title{
Construção de protótipo de eletrofloculação em fluxo contínuo alimentado por energia solar fotovoltaica para purificação de efluentes
}

\section{Samara Pereira Vieira, Luiz Antonio Pimentel Cavalcanti*}

Instituto Federal de Educação, Ciência e Tecnologia da Bahia. Departamento de Ensino. Coordenação de Engenharia Elétrica. Av. Marcondes Ferraz, 200. Bairro General Dutra. Paulo Afonso-BA, Brasil (CEP 48607-000). E-mail: luiz.cavalcanti@ifba.edu.br.

Resumo. A produção de efluentes nos mais variados setores industriais vêm favorecendo a degradação ambiental, especialmente quando não tratados e dispostos no solo ou mananciais hídricos, por essa razão, o principal objetivo desse trabalho foi dimensionar e construir um protótipo de eletrofloculação sob fluxo contínuo alimentado por energia solar fotovoltaica para o tratamento o efluentes de forma que o enquadre às normas estabelecidas pela Resolução CONAMA no 430/2011. Os parâmetros usados para o dimensionamento do reator foram a condutividade, distância entre os eletrodos, controle de vazão do reator e duração de tempo reacional baseados tanto em trabalhos já realizados bem como em trabalhos de otimização de eletrofloculação encontrados na literatura cientifica. A fim de constatar a eficiência do reator de eletrofloculação a fluxo contínuo para purificação de águas residuais foi realizado teste com o efluente residual têxtil separando o mesmo em duas partes para que pudesse ser feita a comparação do efluente antes e após o tratamento. Por meio das análises obtidas foi possível verificar uma redução significativa de DQO (83\%) $\mathrm{DBO}_{5}(54 \%)$ e cor aparente $(84 \%)$. Os resultados obtidos constataram que o efluente se enquadrou nas normas estabelecidas pelo Conselho Nacional do Meio Ambiente (CONAMA), dessa forma possibilitando que o mesmo possa ser utilizado em diversas aplicações como a produção de percloreto de ferro, lavagem de pisos, descarte nos corpos hídricos entre outras aplicações.

Palavras-chave: Tratamento de efluentes; Eletrofloculação em fluxo contínuo; Energia solar fotovoltaica.

Abstract. Construction of the eletrofloculation prototype a continuous flow supplied by solar photovoltaic energy for purification of effluents. The production of effluents in the most varied industrial sectors has favored environmental degradation, especially when not treated and disposed in the soil or water sources, for this reason, the main objective of this work was to design and construct a prototype of electroflocculation under a continuous flow fed by photovoltaic solar energy to treat the
Recebido:

$15 / 04 / 2018$

Aceito:

$27 / 04 / 2018$

Publicado:

$30 / 04 / 2018$

Acesso aberto

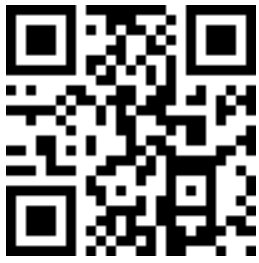

ORCID

(C) $0000-0001-5491-8720$

Samara Pereira Vieira

D 0000-0003-4932-9387

Luiz Antonio Pimentel Cavalcanti 
effluents in a way that meets the same standards established by CONAMA Resolution 430, May 13, 2011. The parameters used for the design of the reactor were conductivity, distance between the electrodes, reactor flow control and reaction time duration based on already performed works as well as on electroflocculation optimization works found in the scientific literature. In order to verify the efficiency of the continuous flow electrocolection reactor for wastewater purification, a residual wastewater effluent test was performed, separating it into two parts so that the effluent could be compared before and after treatment. By means of the analysis, it was possible to verify a significant reduction of COD (83\%) BOD5 (54\%) and apparent color (84\%). The results showed that the effluent conformed to the standards established by The National Environment Council (CONAMA), thus enabling it to be used in several applications such as the production of iron perchloride, washing of floors, disposal in the water bodies among other applications.

Keywords: Effluent treatment; Continuous flow electroflocculation; Photovoltaic solar energy.

\section{Introdução}

Todas as atividades humanas, seja ela industrial ou não, implicam na geração de resíduos. Existem diversos agentes poluentes como óleos, corantes, graxas, dentre outros subprodutos que causam inúmeros problemas ambientais, principalmente quando são descartados de maneira incorreta podendo vir a contaminar outros corpos d'água. Grande parte desses subprodutos são provenientes de atividades das refinarias de petróleo, indústrias químicas, têxteis e farmacêuticas (Richter, 2009).

Já existe uma grande diversidade de procedimentos físicos, químicos e biológicos acessíveis para promover o tratamento de águas residuais procedentes de variadas atividades humanas. A finalidade desses tratamentos é de promover a transferência de fase do material do efluente de interesse e se possível, transfigurar os agentes com alta toxidade em compostos inertes (Cerqueira e Marques, 2011).

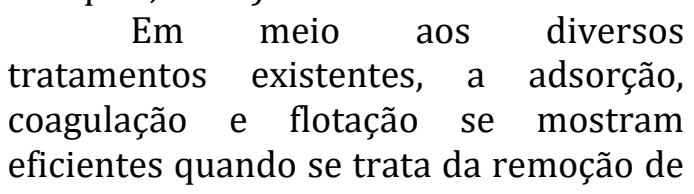

compostos de interesse de matrizes complexas. Nesse sentido, o tratamento eletroquímico aparece como uma alternativa viável para realizar a oxidação e transferência de fase do material orgânico de interesse. A tecnologia de coagulação eletroquímica se trata de uma técnica que tem se mostrando bastante promissora, e por essa razão vem sendo empregada em diversas pesquisas no que tange $o$ tratamento de diversos efluentes, que variam desde águas residuais até água potável (Krithika et al., 2013)

A eletrofloculação, eletroflotação ou eletrocoagulação como também pode ser denominada tem o propósito de tratar efluentes complexos, com mistura de diferentes substâncias de maneira eficiente, econômica e sustentável, o que viabiliza seu uso no tratamento de efluentes de indústria têxtil. A utilização dessa técnica para o tratamento de águas residuais pode ser considerada uma tecnologia de instrumentação e operação simples, que envolve a utilização de um par de placas metálicas de sacrifício, comumente de alumínio ou ferro, e a aplicação de corrente elétrica, que através de reações eletroquímicas gera coagulantes in situ. Desse modo, diminui 
a chance de geração de subprodutos e reduz a produção de lodo (Fleck et al., 2013).

Contudo, segundo Singh (2012) o consumo de energia elétrica pode ser dispendioso em algumas regiões do país para aplicação no tratamento de águas residuais através da eletrofloculação, fazendo com que o processo se torne inviável economicamente. No entanto o uso de sistema fotovoltaico como fonte para geração de corrente elétrica para o processo pode ser utilizado para $o$ tratamento de diversos tipos de efluentes com os mesmos resultados daqueles obtidos pelo uso da energia elétrica da rede, porém com baixo custo além de se tratar de um tipo de energia limpa e renovável.

Partindo destes princípios, Vieira et al. (2015) realizou a aplicação da técnica da eletrofloculação com o uso da energia solar fotovoltaica para tratar águas de lavagem do biodiesel, visto que, o biodiesel é um biocombustível usualmente obtido por meio da transesterificação alcalina homogênea, na qual recorre à etapa de purificação com separação da glicerina produzida. Nesse sentido, na água de lavagem resultante da etapa de purificação do biodiesel é contida uma grande quantidade de resíduos, que requer um tratamento antes do seu reuso ou descarte (Brito et al., 2012).

Nas análises do efluente residual da água de lavagem do biodiesel realizadas pós-eletrofloculação com eletrodos de ferro, Vieira et al. (2017) constataram que os valores obtidos foram enquadrados nas condições estabelecidas pela Resolução CONAMA no 430/2011 (Brasil, 2011). 0 pH da água de lavagem situou-se próximo da neutralidade, conforme as especificações indicadas, bem como foi possível verificar uma redução significativa na turbidez (97\%), DQO (85\%) DB05 (87\%), óleos e graxas (84\%).

Contudo, mesmo com os bons resultados encontrados $\mathrm{o}$ efluente tratado não poderia ser reinserido na cadeia produtiva de biodiesel isso pelo fato do efluente tratado ainda conter um teor de ferro ou alumínio (a depender do eletrodo utilizado) residual alto. A presença de tais metais acelera as reações de autoxidação do biodiesel (Knohte et al., 2006; Junqueira et al., 2015).

Estudos realizados por Vieira et al. (2017), em que a agua residual de biodiesel foi tratada via eletrofloculaçao com eletrodos de alumínio construído a partir de latinhas recicláveis alimentado por energia solar fotovoltaica a um tempo de tratamento de $10 \mathrm{~min}$ foi observado que houve a formação de hidróxido de alumínio e um residual de $\mathrm{KCl}$, tais compostos serviram de base para produção do alúmen de potássio que seria uma possibilidade de aplicação do efluente em questão. Em contrapartida, ao efluente tratado via eletrofloculação por eletrodos de ferro a solução resultante é composta predominantemente de cloreto ferroso $\left(\mathrm{FeCl}_{2}\right)$ como resultado da eletrólise do cloreto de potássio e dispersão do ferro no efluente o que gerou um novo composto após oxidação do mesmo, o percloreto de ferro, com uma aplicação alternativa para produção de placas de circuito impresso.

No presente trabalho, buscou-se dimensionar e construir um protótipo de eletrofloculação alimentado por energia solar fotovoltaica a fluxo contínuo no intuito de verificar a eficiência o processo da eletrofloculação convencional para uma maior escala direcionada a tais aplicações na purificação de águas residuais visto que, a eficiência da reação de eletrofloculação em fluxo contínuo é diretamente dependente das propriedades hidrodinâmicas do reator utilizado.

\section{Materiais e métodos}

Os componentes e equipamentos projetados para construção do protótipo de eletrofloculação sob fluxo contínuo para purificação de efluentes foram 
levantados, planejando-se quais os materiais seriam necessários para construção dos módulos do sistema visando à diminuição do custo global do processo de purificação de efluentes e a exequibilidade do projeto em termos práticos, técnicos e financeiros. Considerou-se, portanto, as seguintes características:
A. Condutividade.
B. Distância entre os eletrodos.
C. Controle de vazão do reator.
D. Duração de tempo reacional.

\section{Construção do protótipo}

O protótipo foi esquematizado conforme mostrado na Figura 1. Neste trabalho foi utilizado sistema composto por: tanque de alimentação com $8 \mathrm{~L}$ (entrada), reator com 4,75 L, e tanque de saída com 3,1 L. Cada um dos compartimentos foi acoplado uma válvula reguladora de vazão visto que todo o processo estará acontecendo por ação da gravidade, e por mangueiras de silicone que representam tubulações com entrada (parte superior) e saída (parte inferior) do reator. Foi desenvolvido um filtro de leito fixo para realizar filtração do efluente pós eletrofloculação construído com camadas de antracito, brita e espuma.

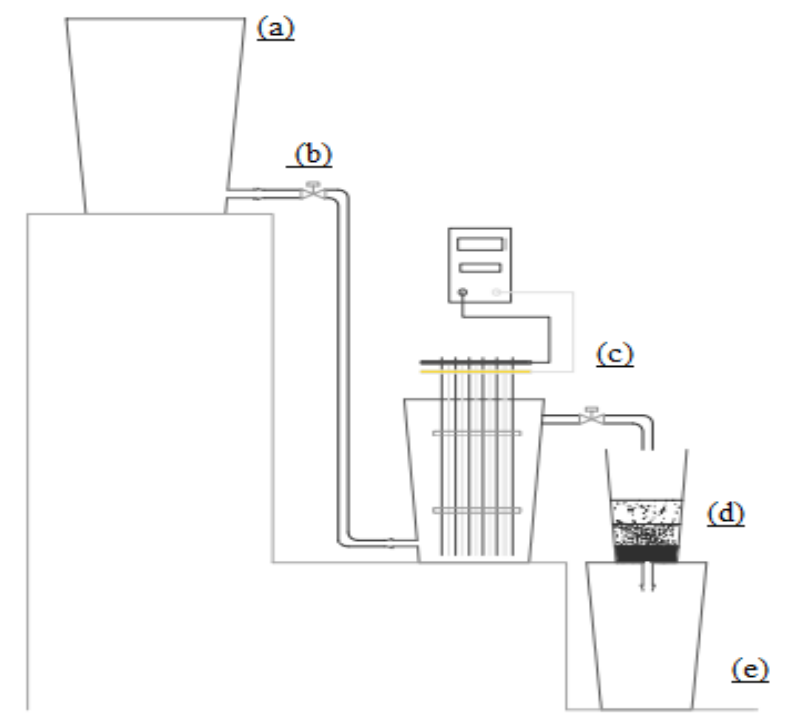

Figura 1. Desenho esquemático do protótipo de eletrofloculação sob fluxo contínuo composto por: (a) tanque de alimentação (entrada), (b) válvula, (c) reator de eletrofloculação, (d) filtro de leito fixo e (e) tanque de saída.

\section{Arranjo das placas}

Para a construção das placas, usou-se o modelo de placas monopolares em paralelo conforme mostrado na
Figura 2. As placas de zinco foram dimensionadas com $12 \mathrm{~cm} \times 24 \mathrm{~cm}$ com o total de 12 placas arranjadas em paralelo com espaçamento de $6 \mathrm{~mm}$ entre elas. 

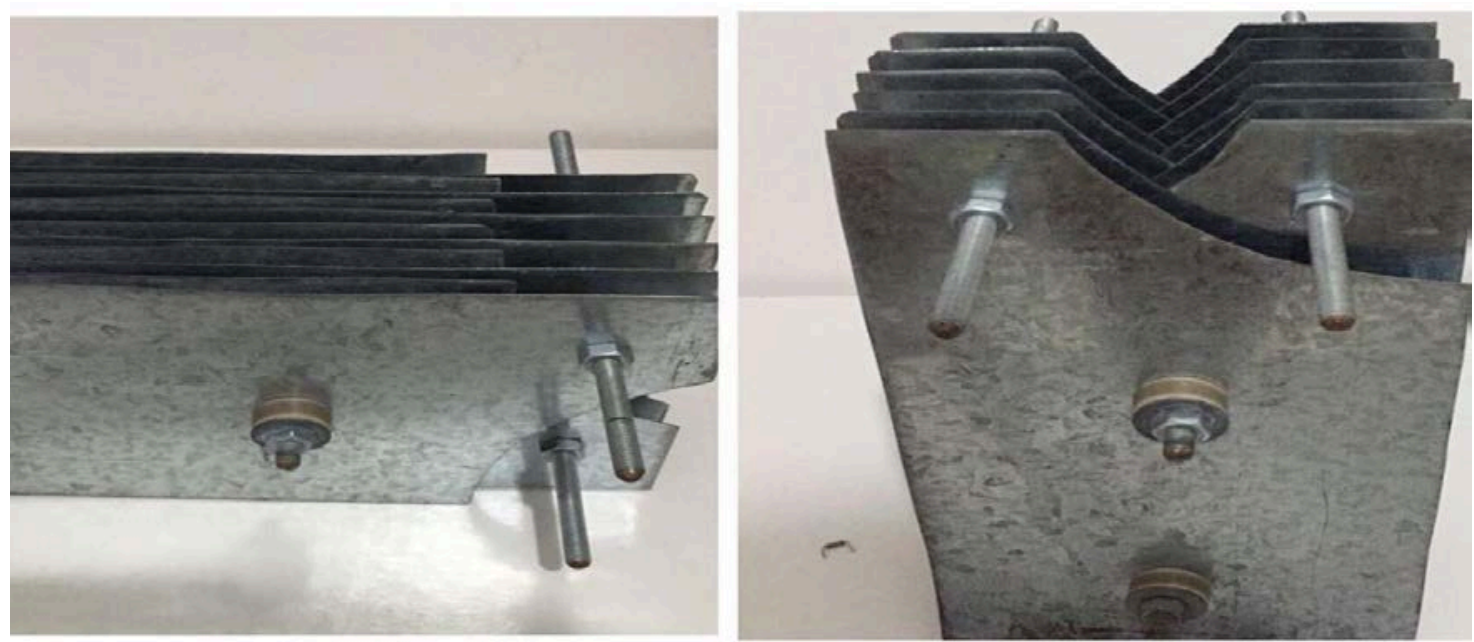

Figura 2. Arranjo de placas monopolares conectadas em paralelo.

\section{Execução do experimento}

Para a análise do efluente têxtil, foi utilizado corante têxtil (TINGECOR) da cor azul no qual foram adicionados 10 $\mathrm{mg} / \mathrm{L}$ do corante. No total foram utilizados $16 \mathrm{~L}$ de água, posteriormente o efluente foi dividido em dois recipientes de 8 litros cada. Um recipiente com o efluente foi armazenado para que pudesse ser feita análise antes do tratamento. A outra parte do efluente foi submetida ao tratamento por meio da eletrofloculação com eletrodos de zinco. Para o efluente submetido à eletroflocução foram adicionados $8 \mathrm{~g}$ de $\mathrm{NaCl}$ como eletrólito e após $12 \mathrm{~min}$ de tratamento a amostra foi submetida ao etapa de filtração. Na sequência foram feitas as análises do efluente bruto e tratado (Figura 3).
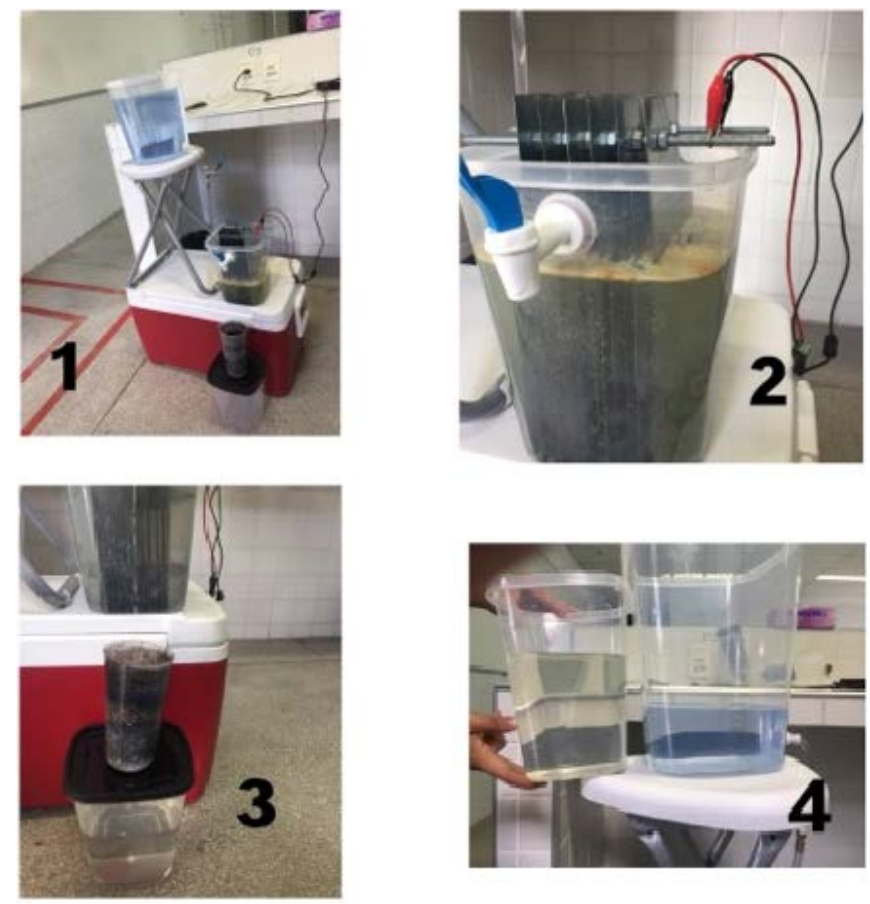

Figura 3. Purificação de efluente têxtil a fluxo contínuo. (1) montagem do reator de eletrofloculação em fluxo contínuo, (2) reator de eletrofloculação, (3) filtro de leito fixo, e (4) comparação do efluente bruto e tratado. 


\section{Sistema fotovoltaico}

Foi utilizado o sistema fotovoltaico para alimentar a fonte de corrente contínua é apresentado na Figura 4 (Nascimento et al., 2015). 0 sistema foi construído para servir como uma central de recargas para celulares, tablets, notebooks, além de servir como local de integração para os estudantes e servidores do Instituto Federal de
Educação, Ciência e Tecnologia da Bahia (IFBA), Campus Paulo Afonso. Sua construção básica conta com a seguinte estrutura: a) Inversor de frequência: Inversor de Onda Modificada Hayonik, $400 \mathrm{~W} 12 \mathrm{~V} / 127 \mathrm{~V}$; b) Controlador de Carga CMTP02 12 V e 10 A; c) Placa Solar: Golden Genesis PV-110E, 110 Wp; d) Bateria: Tudor estacionária $45 \mathrm{Ah}$.

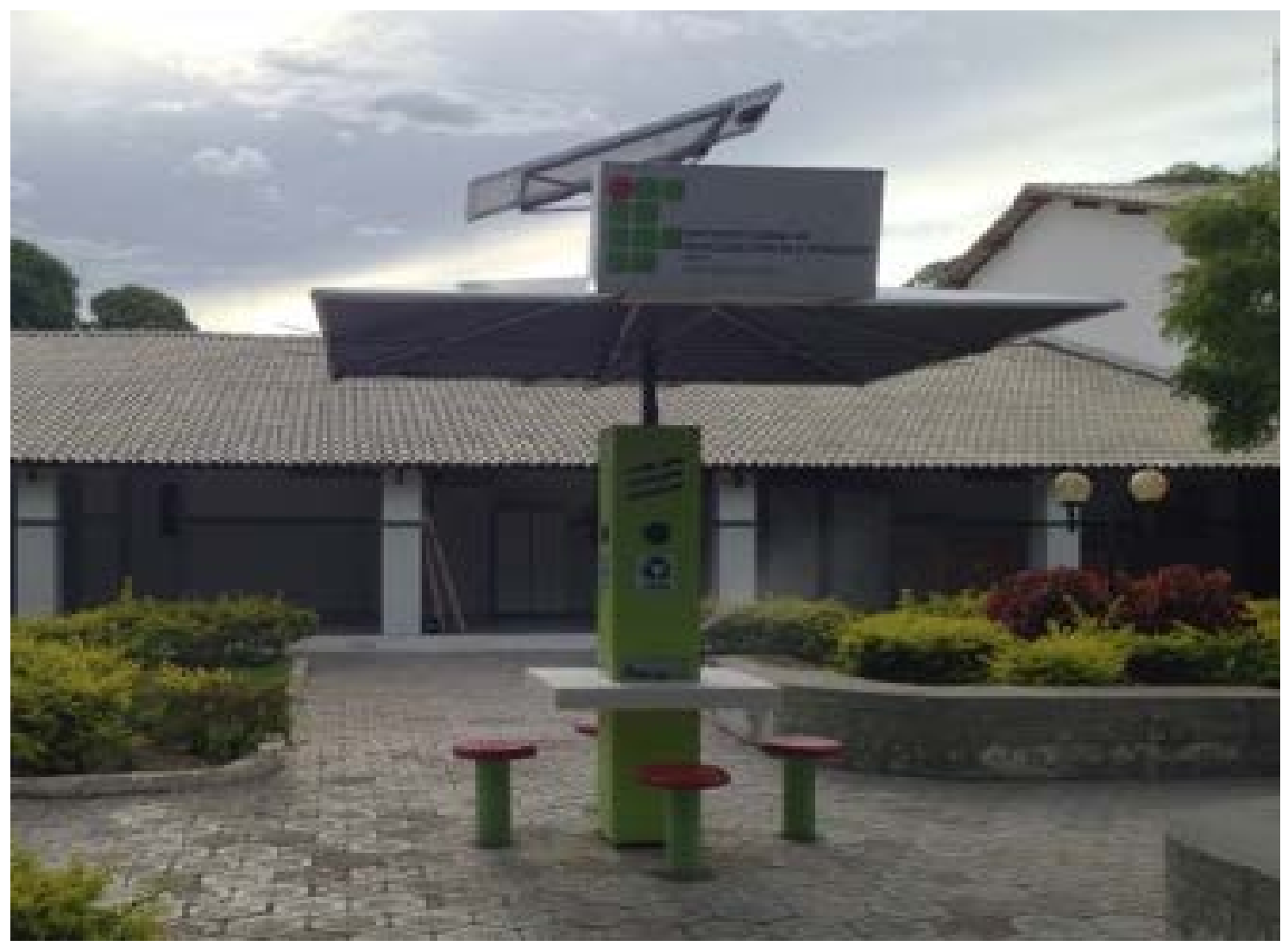

Figura 4. Central de Energia Solar Fotovoltaica, do Instituto Federal de Educação, Ciência e Tecnologia da Bahia (IFBA), Campus Paulo Afonso.

\section{Análise de parâmetros dos efluentes pós-tratamento \\ Determinação do pH. Os valores de $\mathrm{pH}$ das soluções brutas e pós- tratamento das águas residuais foram medidos via pHmetro digital (Quimis, modelo: Q400AS) a $25^{\circ} \mathrm{C}$.}

Determinação de DBO5 e DQO. As análises de Demanda Química de
Oxigênio (DQO) foram realizadas via método colorimétrico (Standard Methods 5220 D), com bloco digestor do tipo TE021 DryBlock Digestor (TECNAL). A DQO nas amostras foi quantificada por espectrofotometria (Spectrophotometer SP1105, Bel Photonics), tomando-se como branco um padrão água destilada (BioClass) (Eaton et al., 2005). As 
análises de Demanda Bioquímica de Oxigênio (DBO5) recorreram ao método definido no Standard Methods 5210 B (Eaton et al., 2005), com determinação quantitativa posterior das amostras (cinco dias) em um oxímetro (Digimed, modelo DM-4D).

\section{Determinação da cor aparente.}

As medidas de cor aparente das águas de lavagem foram realizadas por leituras de absorbância, medidas em espectrofotômetro de UV (Spectrophotometer SP2000UV, Bel Photonics), calibrado com filtro de $460 \mathrm{~nm}$ (Eaton et al., 2005).

\section{Resultados e discussão}

\section{Protótipo}

\section{Dimensionamento do}

O dimensionamento do protótipo foi arranjado de modo que o efluente circulasse do tanque de entrada até o tanque de saída por influência da gravidade sem que se faça necessário o uso de uma bomba ou de um sistema de automação, dessa forma diminuindo os custos com instrumentação e uso de energia no sistema.

0 protótipo reator de eletrofloculação em fluxo contínuo visto é apresentado na Figura 5.

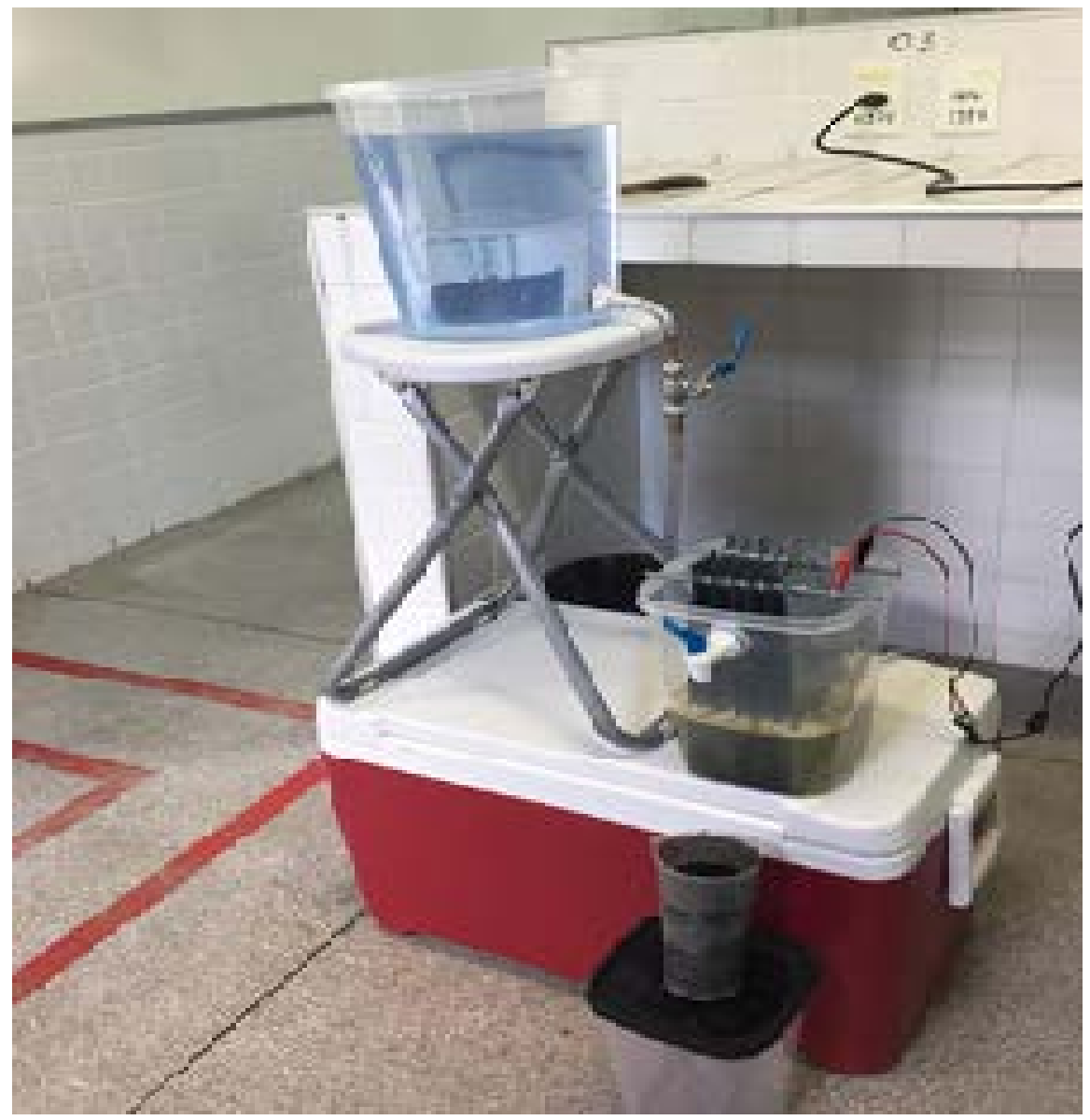

Figura 5. Sistema montado durante o tratamento de efluente textil. 


\section{Espaçamento entre as placas}

A escolha do menor espaçamento entre as placas foi determinada com base em Crespilho e Resende (2004) que diz quanto maior a distância entre os eletrodos, maior diferença de potencial entre elas, logo diminuindo a distância entre as placas estará também otimizando o processo.

\section{Filtro de leito fixo}

Para a filtração do efluente pós eletrofloculação foi confeccionado o filtro de leito fixo, visto que os filtros granulares se mostram mais atrativos devido ao baixo custo de operação e construção além do potencial para remoção simultânea de sólidos ou contaminantes durante a operação (Deuscele et al., 2008). A eficiência dos resultados obtidos na purificação do efluente têxtil, mostrado na Tabela 1 , possui a contribuição direta do uso do filtro de leito fixo.

\section{Uso da energia solar \\ fotovoltaica}

0 uso do sistema solar fotovoltaico trouxe seus benefícios ao sistema, visto que faz o uso de uma energia alternativa e renovável que propõe a diminuição de custos no processo. Isso se $\mathrm{da}$ ao fato da eletrofloculação não ser viável economicamente quando usado a energia da rede convencional oferecida pela concessionária de energia local, fazendo com que seja válida a substituição da energia por uma fonte mais barata para que torne a operação do sistema com menos custos (Singh, 2012).

\section{Análise dos resultados do tratamento de efluente têxtil em fluxo contínuo}

Com base nos resultados obtidos (Tabela 1), foi verificado que os valores de todas as variáveis analisadas provenientes da água residual têxtil, estão situadas fora das normas estabelecidas pela Resolução CONAMA no 430/2011 (Brasil, 2011), exceto o pH, desta forma a água residual não pode ser descartada sem um tratamento prévio.

Nos resultados obtidos após o tratamento por meio da eletrofloculação sob fluxo contínuo, observou-se uma atenuação dos parâmetros analisados, enquadrando o efluente nas especificações necessárias para descarte. $\mathrm{O}$ pH, situou-se próximo do valor estabelecido, porém não atendeu a Resolução devido a formação de hidróxidos no processo de tratamento que elevam o $\mathrm{pH}$ do efluente final, no entanto foi possível obter uma redução significativa de cor aparente (84\%), DQO (83\%) DBO5 (54\%). Na Figura 6, pode ser observada de forma comparativa as águas de efluente têxtil antes e depois do processo de eletrofloculação.

Tabela 1. Características físicas e químicas dos efluentes bruto e tratado via eletrofloculação.

\begin{tabular}{lcccc}
\hline & pH & $\begin{array}{c}\text { Cor Aparente } \\
\text { (UC) }\end{array}$ & $\begin{array}{c}\text { DQO } \\
\text { (mg/L) }\end{array}$ & $\begin{array}{c}\text { DBO5 } \\
\text { (mg/L) }\end{array}$ \\
\hline Efluente bruto & 8,07 & 0,0755 & 741,22 & 235,9 \\
Efluente tratado & 10,25 & 0,0115 & 124,9 & 106,4 \\
$\begin{array}{l}\text { Resolução CONAMA no } \\
430 / 2011\end{array}$ & 5,00 a 9,00 & $\begin{array}{c}\text { Nível natural do } \\
\text { corpo receptor }\end{array}$ & - & $\begin{array}{c}\text { Remoção mínima } \\
\text { de } 60 \%\end{array}$ \\
\hline
\end{tabular}




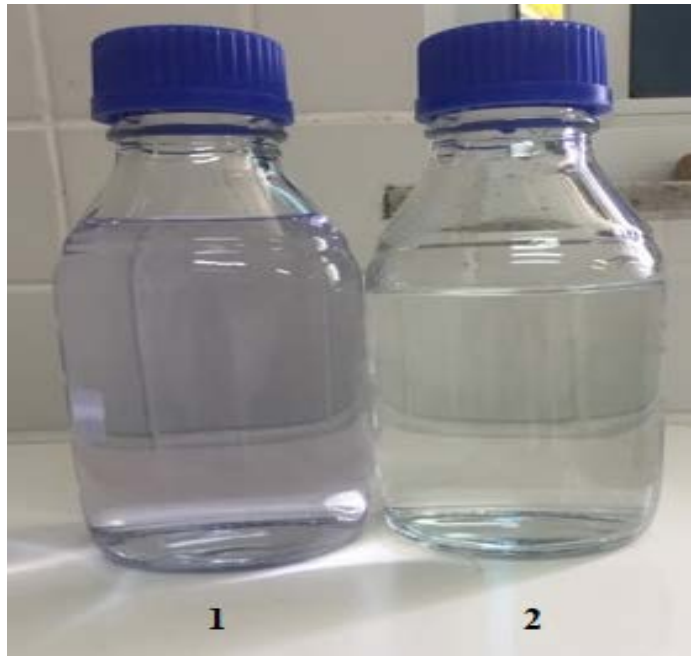

Figura 6. Efluente têxtil. (1) antes da eletrofloculação, (2) após a eletrofloculação.

Com base nos resultados da Tabela 1, pode-se indicar que a água após tratamento no reator em fluxo contínuo poderá ser aplicada em diversas aplicações como a produção de percloreto de ferro como sugerido nos estudos de Vieira et al. (2017), lavagem de pisos, descarte nos corpos hídricos, entre outras aplicações.

\section{Conclusão}

O dimensionamento do protótipo de eletrofloculação em fluxo contínuo mostrou boa eficiência constatada pelos resultados obtidos no efluente têxtil tratado, com redução significativa de cor aparente (84\%), DQO (83\%) e DBO5 (54\%), no qual foi enquadrado dentro dos parâmetros estabelecidos pela Resolução CONAMA no 430/2011 (Brasil, 2011) e, desta forma, podendo ser descartada sem oferecer riscos aos corpos d'água.

0 arranjo das placas tornou 0 processo mais eficiente em fluxo contínuo, bem como o uso dos efeitos da gravidade tornaram $\mathrm{o}$ processo economicamente viável em termos de instrumentação e uso de energia. 0 uso da central fotovoltaica como alimentação do sistema também se mostrou eficiente, uma vez que faz o uso de uma energia limpa e renovável, tornando o processo mais ecologicamente viável e com menos custos.

\section{Declaração de conflito de interesses}

Os autores declaram não haver conflito de interesses.

\section{Referências}

Brasil. Resolução CONAMA no 430, de 13 de maio de 2011. Dispõe sobre as condições e padrões de lançamento de efluentes, complementa e altera a Resolução no 357, de 17 de março de 2005, do Conselho Nacional do Meio Ambiente - CONAMA. Disponível em: <http://www.mma.gov.br/port/conama/legi abre.cfm?codlegi=646>. Acesso em: $20 \mathrm{fev}$. 2018.

Brito, F. J.; Ferreira, O. V. L.; Silva, J.P. Tratamento de água de purificação do biodiesel utilizando eletrofloculação. Quimica Nova, v. 35, n. 4, p.728-732, 2012. https://doi.org/10.1590/S010040422012000400014

Cerqueira, A. A.; Marques, M. R. C. Avaliação do processo eletrolítico em corrente alternada no tratamento de água de produção. Quimíca Nova, v. 34, p.59-63, 2011. https://doi.org/10.1590/S010040422011000100012

Cerqueira, A. A. Aplicação da técnica de eletrofloculação no tratamento de efluentes têxteis. Rio de Janeiro: Universidade do Estado do Rio de Janeiro, 2006. (Dissertação de mestrado).

Cordeiro, R. B.; Alexandre, J. I. S.; Silva, J. P. F.; Sales, D. C. S.; Cavalcanti, L. A. P. Purificação e reutilização de águas residuárias da produção de biodiesel por meio da eletrofloculação. Revista Brasileira de Gestão Ambiental e Sustentabilidade, v. 2, n. 2, p.51-58, 2015. Disponível em: <http://revista.ecogestaobrasil.net/v2n2/v0 2n02a05.pdf>. Acesso em: 20 fev. 2018.

Crespilho, F. N.; Rezende, M. O. O. Eletroflotação: princípios e aplicações. 1. ed. São Carlos: Rima, 2004.

Deuscele, T.; Janouske, U.; Piesche, M. A CFD model describing filtration, regeneration and deposit rearrangement effects in gas filter systems. Chemical Engineering Journal, 
v. 135 , n. $1 / 2, \quad$ p. $49-55, \quad 2008$. https://doi.org/10.1016/j.cej.2007.03.019

Di Bernardo, L.; Dantas, A. D. B. Métodos e técnicas de tratamento de água. São Carlos: Rima, 2005. v. 1.

Eaton, A. D.; Clesceri, L. S.; Rice, E.W.; Greenberg, A. B. (Eds.). Standard methods for the examination of water and wastewater. 21. ed. Washington: American Public Health Association, American Water Works Association and Water Environment Federation, 2005.

Fleck, L.; Tavares, M. H. F; Eyng, E. Utilização da técnica de eletrofloculação para 0 tratamento de efluentes têxteis: uma revisão. Revista EIXO, v. 2, n. 2, p. 27-36, 2013. https://doi.org/10.19123/eixo.v2i2.107

John, S.; Soloman, P A.; Fasnabi, P. A. Study on removal of acetamiprid from wastewater by electrocoagulation. Procedia Technology, v. 24 , p. 619-630, 2016. https://doi.org/ 10.1016/j.protcy.2016.05.147

Junqueira, C. N.; Franco, M. M.; Ruggiero, R.; Borges Neto, W.; Bueno, J. A.; Santos, D. Q. Contaminantes metálicos no biodiesel de soja. Anais do X Congresso Internacional de Bioenergia, São Paulo, 2015.

Knothe, G.; Gerpen, J. V.; Krani, J.; Ramos, L. P. Manual do biodiesel. São Paulo: Edgard Blücher, 2006.

Krithika, R.; Verma, R. J.; Shrivastav, P. S. Antioxidative and cytoprotective effects of andrographolide against CCl4-induced heaptotoxicity in HepG2 cells. Human \& Experimental Toxicology, v. 32, p. 530-543, 2013. https://doi.org/10.1177/096032711245 9530

Nascimento, F. A.; Vieira, S. A.; Andrade Júnior, S. J.; Cavalcanti, L. A. P. Integração de um sistema fotovoltaico isolado e de coleta seletiva de resíduos em um quiosque multi- funcional. Revista Brasileira de Gestão Ambiental e Sustentabilidade, v. 2, n. 2, p. 43-50, 2015. Disponível em: <http://revista.ecogestaobrasil.net/v2n2/v0 2n02a04.pdf>. Acesso em: 20 fev. 2018.

Richter, C. A. Água: métodos e tecnologias de tratamento. 1. ed. São Paulo: Edgard Blücher, 2009.

Singh, G. Electroflocculation on textile dye wastewater. Patiala: Thapar University, 2012. (Dissertação de Mestrado). Disponível em: <http://dspace.thapar.edu:8080/dspace /bitstream/10266/1943/1/electroflocculati on.pdf>. Acesso em: 20 fev. 2018.

Vieira, S. P.; Nascimento, F. A.; Araujo, M. B.; Andrade Junior, S. J.; Cavalcanti, L. A. P. Reuso de latinhas de alumínio recicláveis para tratamento de águas residuais da produção de biodiesel via eletrofloculação. Revista Brasileira de Gestão Ambiental e Sustentabilidade, $\quad$ v. 2, n. 3, p. 145-151, $2015 . \quad$ Disponível em: <http://revista.ecogestaobrasil.net/v2n3/v0 2n03a07.pdf>. Acesso em: 20 fev. 2018.

Vieira, S. P; Oliveira, F. C. F.; Cavalcanti, L. A. P. Síntese do percloreto de ferro a partir das águas residuais da produção de biodiesel tratadas por eletrofloculação para confecção de placas de circuito impresso. Holos, v. 33, n. 1, p. 205-213, 2017. Disponível em: <http://www2.ifrn.edu.br/ojs/index.php/HO LOS/article/view/5116/pdf>. Acesso em: 20 fev. 2018

Informação da Licença: Este é um artigo Open Access distribuído sob os termos da Licença Creative Commons Attribution, que permite uso irrestrito, distribuição e reprodução em qualquer meio, desde que a obra original seja devidamente citada. 